\title{
On electrostatics, covalency, and chemical dashes: physical interactions versus chemical bonds
}

\author{
A. Martín Pendás*, J. L. Casals-Sainz, E. Francisco ${ }^{a}$ \\ September 28, 2018
}

\begin{abstract}
The increasing availability of real space interaction energies between quantum atoms or fragments, that provide a chemically intuitive decomposition of intrinsic bond energies into electrostatic and covalent terms (see for instance Chem. Eur. J. 24, 9101, 2018), evidences the differences between the physicist's concept of interaction and the chemist's concept of bond. We argue that for the former all types of interactions are treated on the same footing, while for the latter only the covalent short-ranged ones have been actually used to build intuition about chemical graphs and chemical bonds. This has lead to overlook the bonding role of long-range Coulombic terms in molecular Chemistry. Simultaneously, blind consideration of electrostatic terms in chemical bonding parlance may lead to confusion. The relation among all these concepts is examined here, and some notes of caution on how to merge them are put forward.
\end{abstract}

Keywords: Chemical bonding, IQA, bond energy.

\section{Introduction}

There are two inextricably linked sides in the chemical bond concept that justify the difficulty to formalize it properly. This Janus character is best exemplified by the bond energy-bond order di-

\footnotetext{
${ }^{[a]}$ Prof. Angel. Martín Pendás, Jose Luis Casals Sainz, Prof. Evelio Francisco. Departamento de Química Física y Analítica. Facultad de Química. Universidad de Oviedo. 33006-Oviedo. Spain.

E-mail: ampendas@uniovi.es
} 
chotomy. [1] A chemical bond has an energetic strength (its bond energy) that is somehow connected to a particular electron count (its bond order). Rather interestingly, neither bond energies nor bond orders are (Dirac) observables. The first vanish in thin air once we pass from diatomics to polyatomics, while the second rely too often on the orbital approximation. [2] Notwithstanding, chemists feel comfortable with such an edifice otherwise built on shifting sands.

Real space analyses in chemical bonding [3] have been shown to ameliorate this undesirable status quo in several ways. By using descriptors based on (reduced) density matrices (RDMs) their results are invariant under orbital transformations, i.e. independent on the particular theoretical framework used to obtain a given wavefunction. Being defined in the physical, not in the Fock or in the orbital space, real space methods recover core chemical concepts like atoms - through the quantum theory of atoms in molecules (QTAIM) [3] — or cores, bond and lone pairs — through the analysis of, for instance, the electron localization function (ELF) $[4,5]$ or the electron localizability indicator (ELI). [6,7]

Once these three-dimensional regions are available electron and electron pair counting becomes easy, by means of spatial integration of the density and the pair density, respectively. Similarly, the energy content of an atomic region, as well as the interaction energy between any pair of these 3D atoms, can be rigorously obtained through the interacting quantum atoms (IQA) formalism. $[8,9]$ There exist many other energy decomposition analyses (EDAs), mostly based on the orbital paradigm, that tend to partition the molecular energy from (usually) two previously defined fragments. This is done either through perturbation theory, [10-12] via the construction of fictitious intermediate states in an attempt to separate bond formation into a set of finite steps, each capturing a relevant physical processes, as pioneered by Morokuma, [13-17] or through mixed strategies. [18-21] A critical comparison of EDAs and IQA has recently been presented. [22]

IQA provides a consistent way to approach the bond energy-bond order problem. For instance, it has recently been shown [23] that the duality may indeed be dissolved: the interaction energy between two real space atoms is directly related to electron count measures. To first order in a specific multipolar expansion the electrostatic component of this interaction is given by the interatomic charge transfer, while the covalent contribution comes from the interatomic share of electron pairs, all in agreement with chemical wisdom.

It is a common feature of the aforementioned real space techniques that they provide interatomic 
electron counting and interatomic energetic descriptors between any pair of atoms of the system, not only between those pairs that are conventionally distinguished as bonded. This raises a number of interesting questions, like when to consider two atoms bonded, i.e. when to draw a dash between them, or what energy components to associate to dashes, if any. Answering these questions is important in order to build proper bridges between the language of physicists, where interactions dominate, and that of chemists, where complexity is hidden into bonds.

Using real space machinery, it may be shown that very simple sum rules exist in both the electron counting and the energy decomposition cases: $[8,9]$

$$
\begin{aligned}
& \mathrm{N}=\sum_{\mathrm{A}} \lambda^{\mathrm{A}}+\sum_{\mathrm{A} \neq \mathrm{B}} \delta^{\mathrm{AB}}, \\
& \mathrm{E}=\sum_{\mathrm{A}} \mathrm{E}_{\text {self }}^{\mathrm{A}}+\sum_{\mathrm{A} \neq \mathrm{B}} \mathrm{E}_{\mathrm{int}}^{\mathrm{AB}} .
\end{aligned}
$$

In the first expression, the total number of electrons of a system $\mathrm{N}$ is written as a sum of those localized in each atom, $\lambda^{\mathrm{A}}$, and those delocalized between the A, B pair, $\delta^{\mathrm{AB}}$. These two descriptors are usually known as the localization (LIs) and delocalization (DIs) indices, respectively. Dls are covalent bond orders. [24] Similarly, the second expression writes the total energy as a sum of atomic contributions, the so-called atomic self-energies, $\mathrm{E}_{\text {self }}^{\mathrm{A}}$, and the pairwise additive interatomic interaction energies, $E_{i n t}^{A B}$. [8] $E_{\text {self }}^{A}$ contains all the energetic contributions of the particles contained in the $\mathrm{A}$ atomic region among themselves: the kinetic energy of the electrons, the electron-own nucleus attraction and the interelectron repulsion. It is well known [8] that the changes in these contributions upon bonding from their values in vacuo tend to cancel each other, so that self-energies are close (in a chemical scale) with respect to the free atomic energies. Interaction energies behave as intrinsic bond energies, [25] measuring the energy change, taken from the in-the-molecule atomic references, that occurs when the two quantum atoms are allowed to interact. They are composed of the previously mentioned electrostatic and covalent contributions,

$$
E_{\text {int }}^{A B}=E_{\text {els }}^{A B}+E_{\text {cov }}^{A B} \text {. }
$$

The structure of Eq. 2 is familiar in atomistic simulations, being immediately recognized as a slightly generalized version of the pair-potential ansatz. It is thus easily accepted in a physicists environment. Assigning bond energies and bond orders to all atomic pairs is, however, an uncommon practice in Chemistry. We have advocated elsewhere [25] that this ansatz should be fostered, 
for it solves many controversial bonding issues. Since we are here interested in understanding interactions, we will drop the one-atom terms from now on.

The electrostatic term $\mathrm{E}_{\text {els }}^{\mathrm{AB}}$ is simply the classical Coulombic interaction energy of the total (electron plus nuclear) densities of $A$ and $B$, while the covalent one involves the exchange-correlation density, that measures deviations of the pair density from the independent particle approximation. [9]

A note of caution is due. Given that the classical Coulombic interaction between two point charges $Q^{A}$ and $Q^{B}$ frequently appears in the following discussion, and to avoid any confusion, we point out from the outset that $E_{\text {els }}^{A B}$ is computed here exactly, so that it gathers all the existing interactions between two finite electron and nuclear distributions: $E_{\text {els }}^{A B}=\int_{A} d r_{1} \int_{B} d r_{2} \rho_{t}\left(r_{1}\right) \rho_{t}\left(r_{2}\right) / r_{12}$. Here, $\rho_{\mathrm{t}}$ is the total (electron plus nuclear) charge density. This includes as the main term the classical interaction between the point charges, but also the multipolar interactions at all ranges (i.e. charge-dipole, dipole-dipole, charge-quadrupole, etc) between both densities, as well as short range interactions (charge penetration energies) that cannot be represented within the multipolar approximation. In the same way, $\mathrm{E}_{\mathrm{cov}}^{\mathrm{AB}}$ is obtained also by using the exact exchange-correlation density of the quantum-mechanical method that is being used in each case.

As explained, a multipolar expansion can be used $[26,27]$ to show that, to first order in the interatomic distance, $\mathrm{R}_{\mathrm{AB}}$,

$$
\mathrm{E}_{\mathrm{els}}^{\mathrm{AB}} \sim \frac{\mathrm{Q}^{\mathrm{A}} \mathrm{Q}^{\mathrm{B}}}{\mathrm{R}_{\mathrm{AB}}}, \quad \mathrm{E}_{\mathrm{cov}}^{\mathrm{AB}} \sim-\frac{1}{2} \frac{\delta^{\mathrm{AB}}}{\mathrm{R}_{\mathrm{AB}}},
$$

$\mathrm{Q}^{\mathrm{A}}$ denoting the net atomic charge of atom $\mathrm{A}$. Covalent energies are then bond order measures, and vice versa. This is pleasant to a chemist's eye.

\section{The chemist's bond versus the physicist's interaction}

Once these concepts have been briefly reviewed, we notice that over the last decade a number of works have clearly shown [28-30] that chemical graphs, i.e. dashes, are primarily related to $E_{c o v}^{A B}$. It was first noted [28] that the bond critical points of the QTAIM indicate primary exchange channels, so that an atom builds bond paths with those neighbors with which $\mathrm{E}_{\mathrm{cov}}^{\mathrm{AB}}$ is maximized. This was followed by recognizing that $E_{c o v}^{A B}$ itself pinpoints the chemical graph. [29] Given the general exponential decay of exchange-correlation energies with distance, the set of $\mathrm{E}_{\mathrm{cov}}^{\mathrm{AB}}$ values between the pairs of all the atoms in a molecule, a square matrix of covalent energies, can be easily classified into categories. 
We call them primary, secondary, etc, covalent interactions. The primary set provides the chemical dashes, while the rest inform, hierarchically, about residual interactions, a very valuable information.

The bonds of chemistry are in this manner connected to physical interactions, closing the circle: all atoms in a molecule interact with each other (the physicist's view), and it is the covalent energy contribution that is used to define bonds (the chemist's view). It is clear from Eq. 4 that a maximization criterion of the bond order can also be used to define graphs, and that chemists have been using electron delocalization, the underlying quantity behind $\mathrm{E}_{\mathrm{cov}}$ or $\delta$, to construct chemical models.

Why is $E_{\text {els }}^{A B}$ missing from the above discussion? Contributing to answering this question is the aim of this work. In what follows we try to understand the role of $E_{\text {els }}^{A B}$ in bonding energetics. In passing, we also show possible sources of confusion, and we vindicate the importance of electrostatics, a fundamental component of all current knowledge on intermolecular interactions that is inexplicably forgotten in single molecule bonding models. We base our reasoning on two simple ideas: (i) normal matter is electroneutral, so electrostatic interactions tend to cancel out; (ii) covalent and electrostatic energies are short- and long-ranged, respectively. $E_{\text {cov }}$ has thus been used to sculpt single molecule know-how, while $E_{\text {els }}$ gains importance at large distances.

It is then the fact that chemical processes like bond formation and bond breaking are usually very short-ranged which lies behind using electron delocalization measures and covalent energies to define molecular graphs. These objects are intimately related to the orbital picture, which therefore ignores electrostatic terms.

Let us first briefly review the magnitude of the energetic quantities we will be using by taking the $\mathrm{H}_{2}$ and LiF molecules as examples. An IQA full configuration interaction calculation in the former [8] provides $\mathrm{E}_{\mathrm{int}}^{\mathrm{HH}}=-121.9 \mathrm{kcal} / \mathrm{mol}$, with $\mathrm{E}_{\mathrm{cov}}^{\mathrm{HH}}=-148.4$ and $\mathrm{E}_{\mathrm{els}}^{\mathrm{HH}}=26.5 \mathrm{kcal} / \mathrm{mol}$. The electrostatic contribution is destabilizing as it must be when two neutral non-overlapping charge distributions interact. [8] In contrast, a CCSD calculation in LiF [25] provides an opposite energetic partition of the $\mathrm{E}_{\mathrm{int}}^{\mathrm{LiF}}=-208.1 \mathrm{kcal} / \mathrm{mol}$, with $\mathrm{E}_{\mathrm{cov}}^{\mathrm{LiF}}=-28.8$ and $\mathrm{E}_{\mathrm{els}}^{\mathrm{LiF}}=-179.3 \mathrm{kcal} / \mathrm{mol}$. Interestingly, assuming point net QTAIM charges for LiF provides a very good approximation to $E_{\text {els }}^{\mathrm{LiF}}, Q^{A} Q^{B} / R_{A B}=-184.5$ $\mathrm{kcal} / \mathrm{mol}$ (this is only the case in very ionic compounds). All in all, in these two paradigmatic cases the interatomic interaction energies are consistent with the computed dissociation energies, -105.9 $\mathrm{kcal} / \mathrm{mol}$ in $\mathrm{H}_{2}$ and $-131.7 \mathrm{kcal} / \mathrm{mol}$ in LiF. As expected, $\mathrm{D}_{\mathrm{e}}$ in $\mathrm{H}_{2}$ is dominated by covalency, and by electrostatics in LiF. 


\section{Electrostatics and chemical dashes}

Jumping from the LiF diatomic to the LiF crystal is instructive, revealing the first problem associated to using $E_{\text {els }}$ for chemical purposes. The total electrostatic interaction (well approximated by point charge calculations) leads to the Madelung series, which is non-convergent unless special methods are used (e.g. the Ewald summation technique [31]). For instance, the point charge $E_{\text {els }}^{\text {LX }}$ energy between a $\mathrm{Li}^{+}$cation and an $\mathrm{X}^{ \pm|Q|}$ species in the LiF lattice assuming $|\mathrm{Q}| \sim 0.94|\mathrm{e}|$ decays like $\mathrm{Q}^{2} / \mathrm{R}_{\mathrm{LiX}} \simeq \pm 554 / \mathrm{R}_{\mathrm{LiX}} \mathrm{kcal} / \mathrm{mol}\left(\mathrm{R}_{\mathrm{LiX}}\right.$ in au). Since in the rock-salt structure the first neighbor distance is 3.8 au and the eighth neighbor (a 1,9 interaction in ordinary chemical parlance) of an ion is an opposite charge counterion at a distance just three times larger than the first neighbor separation, the $\mathrm{E}_{\mathrm{els}}^{\mathrm{LiF}(1,9)}$ value for such a pair would be as large as $\sim-50 \mathrm{kcal} / \mathrm{mol}$ (a third of its first neighbors value). At this distance $E_{\text {cov }}$ is negligible for all purposes, so $E_{\text {int }}^{\mathrm{LiF}(1,9)}$ would be also about -50 $\mathrm{kcal} / \mathrm{mol}$. Should we draw a dash between 1,9 neighbors based on this large $\mathrm{E}_{\text {int }} \approx \mathrm{E}_{\text {els }}$ value? The chemical answer to this question is no, and thus electrostatic energies have been overlooked to build chemical graphs for good reasons: they decay too slowly. Justifiably, in the LiF crystal we still use $E_{\text {cov }}$ to assign dashes, no matter that $E_{\text {els }}$ is larger in magnitude.

In any case, slow decay by no means implies irrelevance. If non-negligible charge flows exist in a system, like the ones occurring in the LiF diatomic or crystal, this must be because the final energetic balance of (partial) ionization pays off. This is nothing but the textbook Born-Haber cycle, which can be restated in terms of atomic self-energies. Promoting the free $\mathrm{Li}$ and $\mathrm{F}$ atoms into their in-the-molecule states in the LiF diatomic costs [25] 132.1 and $-55.7 \mathrm{kcal} / \mathrm{mol}$, respectively. These add to a $76.4 \mathrm{kcal} / \mathrm{mol}$ global penalty that is more than compensated by the mutual $-170.3 \mathrm{kcal} / \mathrm{mol}$ electrostatic attraction between the formed ions. Similarly, the full Madelung energy is essential to account for the total lattice energy of the LiF crystal. However, its long-range character makes it an inadequate energetic quantity to properly define chemical bonds.

\section{Electroneutrality}

The role of electroneutrality is particularly evident when polar and non-polar interactions coexist in a system, and its misuse may lead to severe misinterpretations of the meaning of $E_{i n t}^{A B}$. This can be very nicely exemplified by comparing the energetics of the ethylene and tetrafluoroethylene 


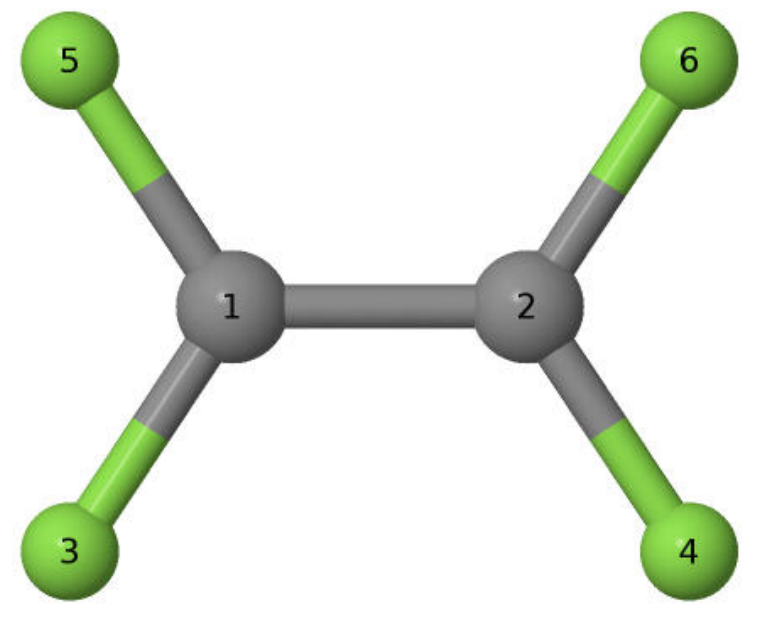

Figure 1: The $\mathrm{C}_{2} \mathrm{X}_{4}$ numbering used in this work.

molecules. We performed M06-2X//def-QZVPD calculations on both and analyzed their wavefunction with the PROMOLDEN code. [32]

Fig. 1 shows the labelling that we will be using in what follows. The simplistic electronic structure of ethylene is found across textbooks, and is dominated by $\sigma \mathrm{C}-\mathrm{H}$ bonds and either a $\sigma-\pi$ or a twin banana double $-\mathrm{C}=\mathrm{C}-$ link. $\mathrm{C}_{2} \mathrm{~F}_{4}$ displays a number of peculiarities in its dissociation curve, [33] but at the equilibrium geometry it may be again described by the same bonding pattern. Polarity, however, makes a difference: the net charge of the $\mathrm{H}$ atoms is very small in ethylene, $\mathrm{Q}(\mathrm{H})=-0.002$ $\mathrm{au}$, while it is hundreds of times larger in magnitude for the fluorines in $\mathrm{C}_{2} \mathrm{~F}_{4}, \mathrm{Q}(\mathrm{F})=-0.670$ au. This leads to almost neutral carbons in the former molecule, but to highly positively charged ones in the latter. Since the $-\mathrm{CH}_{2}$ or $-\mathrm{CF}_{2}$ fragments are neutral, examining covalent and electrostatic contributions in these two systems provides illuminating data.

Table 1 contains the interaction energy data for all non-equivalent atomic pairs in both systems. A result stands out over all others. The $\mathrm{C}-\mathrm{C}$ interaction energy is destabilizing for the $\mathrm{C}_{2} \mathrm{~F}_{4}$ molecule. Thus, $E_{\text {int }}$ itself cannot be used as a chemical graph indicator. The meaning of this result will come clear in the following. Notice, as already pointed out, that $\mathrm{E}_{\mathrm{cov}}$ and $\delta$ are good estimators of chemical intution. The decrease in the bond order from unity that is found in a single polar bond like the C-F one is well understood. [34] Secondary and tertiary interactions are also easy to read from the table, 
Table 1: IQA Interaction data for the $\mathrm{C}_{2} \mathrm{X}_{4}$ systems. The first row for each interaction refers to ethylene and the second to $\mathrm{C}_{2} \mathrm{~F}_{4}$. All energetic data in $\mathrm{kcal} / \mathrm{mol}$.

\begin{tabular}{lrrrr}
\hline Pair & $\mathrm{E}_{\text {int }}$ & $\mathrm{E}_{\text {cov }}$ & $\mathrm{E}_{\text {els }}$ & $\delta$ \\
\hline C-C & -299.6 & -341.8 & 42.2 & 1.893 \\
& 46.7 & -312.1 & 358.7 & 1.521 \\
\hline C-X(1-3) & -164.9 & -187.8 & 22.8 & 0.976 \\
& -496.9 & -152.8 & -244.0 & 0.742 \\
\hline C-X(1-4) & -4.2 & -5.7 & 1.5 & 0.069 \\
& -140.1 & -12.3 & -127.8 & 0.132 \\
\hline X-X(3-4) & -0.4 & -0.6 & 0.2 & 0.039 \\
& 57.0 & -3.3 & 60.3 & 0.035 \\
\hline X-X(3-5) & -2.3 & -3.1 & 0.8 & 0.039 \\
& 62.3 & -20.9 & 83.2 & 0.167 \\
\hline X-X(3-6) & -0.6 & -0.7 & 0.1 & 0.015 \\
& 47.6 & -1.3 & 48.8 & 0.024
\end{tabular}

including several stereoelectronic effects. As pointed out recently, $[27,35] \mathrm{E}_{\text {cov }}$ decays exponentially with distance in insulating-like systems, so an order of magnitude distinguishes 1,2 from 1,3 and 1,3 from 1,4 terms. $E_{\mathrm{els}}$, on the contrary, is clearly dominated by the net charge Coulombic interaction. It is positive (due to further order multipolar terms) for the $\mathrm{C}-\mathrm{H}$ bond, grossly stabilizing in the $\mathrm{C}-\mathrm{F}$ case, for instance, and very small for the 3-4 and 3-6 $\mathrm{H}-\mathrm{H}$ interactions. However, these two last values (the 3-4 and 4-6 X-X interactions) become considerable in magnitude (60 and $49 \mathrm{kcal} / \mathrm{mol}$, respectively) in $\mathrm{C}_{2} \mathrm{~F}_{4}$.

The polarization of the electron density in both systems that leads to such different electrostatic terms has measurable consequences. The electrostatic potential, for instance, is definitely different, so long-range intermolecular interactions will differ accordingly. Fig. 2 shows how the electrophilic/nucleophilic regions are almost complementary in the two systems. We stress that standard orbital reasoning in bonding theory is energetically mapped onto $\mathrm{E}_{\mathrm{cov}}$, and that $\mathrm{E}_{\mathrm{els}}$ is often skipped, so that the consequences of the slow decay and long-range of electrostatic interactions is disregarded.

The reasons why $E_{\text {els }}$ plays such a minor role in the orbital based paradigm can be grasped already from Table 1. Let us consider the $\mathrm{C} 1$ atom and ask about its electrostatic interaction with the C2-X4-X6 group. This adds to $45.2 \mathrm{kcal} / \mathrm{mol}$ in $\mathrm{C}_{2} \mathrm{H}_{4}$ and to $103.1 \mathrm{kcal} / \mathrm{mol}$ in $\mathrm{C}_{2} \mathrm{~F}_{4}$. Thus, the difference in the magnitude of the net charge of $C$ in both systems, 0.004 au in ethylene, $1.340 \mathrm{au}$ 

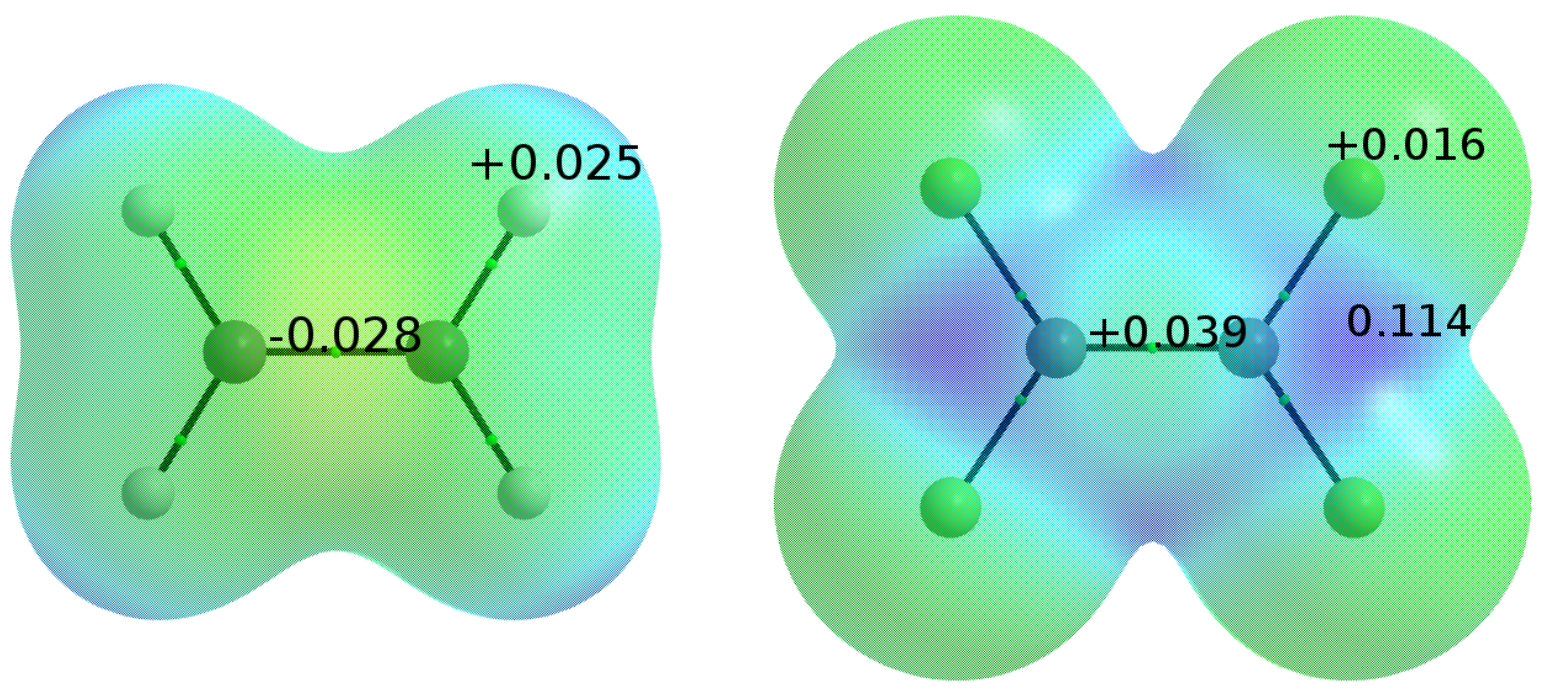

Figure 2: Electrostatic potential mapped onto the $|\rho|=0.01$ au isosurfaces in $\mathrm{C}_{2} \mathrm{H}_{4}$ (left) and $\mathrm{C}_{2} \mathrm{~F}_{4}$ (right). The electrostatic potential color scale spans from -0.12 au (red) to +0.12 au (blue). Selected values have been superimposed at relevant positions of the density isosurface. The minimum and maximum values of the electrostatic potential on the density isosurfaces are $-0.028,+0.091$ au for $\mathrm{C}_{2} \mathrm{H}_{4}$ and $+0.003,+0.129$ au for $\mathrm{C}_{2} \mathrm{~F}_{4}$. Computational conditions as detailed in the text.

Table 2: IQA data for the interaction of the two $-\mathrm{CX}_{2}$ fragments in the $\mathrm{C}_{2} \mathrm{X}_{4}$ systems. Energies in $\mathrm{kcal} / \mathrm{mol}$.

\begin{tabular}{lrrrr}
\hline Pair & $\mathrm{E}_{\text {int }}$ & $\mathrm{E}_{\text {cov }}$ & $\mathrm{E}_{\text {els }}$ & $\delta$ \\
\hline $\mathrm{X}=\mathrm{H}$ & -318.4 & -367.3 & 49.0 & 2.277 \\
$\mathrm{X}=\mathrm{F}$ & -304.7 & -370.7 & 66.0 & 2.167
\end{tabular}


in $\mathrm{C}_{2} \mathrm{~F}_{4}$, translates into an eight-fold increase in the $\mathrm{C}-\mathrm{C} \mathrm{E}_{\text {els }}$, that passes from 42 to $359 \mathrm{kcal} / \mathrm{mol}$, respectively. When the neutral $-\mathrm{CX}_{2}$ fragment is considered instead, this difference dampens dramatically and $\mathrm{E}_{\mathrm{els}}$ differs by just $57.9 \mathrm{kcal} / \mathrm{mol}$. Electrostatic interactions tend to cancel out due to electroneutrality.

Cancellation effects are unveiled in its full glory if we consider the interaction between the two $-\mathrm{CX}_{2}$ groups, shown in Table 2. Notice how important these cancellations are. The completely disparate C-C $\mathrm{E}_{\text {int }}$ values of Table 1, -299.6 and $46.7 \mathrm{kcal} / \mathrm{mol}$ for $\mathrm{C}_{2} \mathrm{H}_{4}$ and $\mathrm{C}_{2} \mathrm{~F}_{4}$, respectively, now differ in less than $14 \mathrm{kcal} / \mathrm{mol}$. The electrostatic interaction between the $-\mathrm{CX}_{2}$ groups is obviously different in both cases, but the difference, $17 \mathrm{kcal} / \mathrm{mol}$, is almost 20 times smaller than the one between the $\mathrm{C}-\mathrm{C} \mathrm{E}_{\mathrm{els}}$ 's, $317 \mathrm{kcal} / \mathrm{mol}$. Moreover, a trade between $\mathrm{E}_{\mathrm{cov}}$ and $\mathrm{E}_{\text {els }}$ can be seen. Interestingly, see below, $\mathrm{E}_{\text {cov }}$ between the two $-\mathrm{CX}_{2}$ fragments tells how similar the covalent terms in ethylene and $\mathrm{C}_{2} \mathrm{~F}_{4}$ are.

\section{Joining the pieces}

Now the relation between the physicist-like concept of interaction and the chemical-like bond construct becomes clearer. The real space quantum atom is an object in space. If the object is charged, a long-ranged Coulombic interaction will necessarily appear with other charged regions. Except in extreme cases, like the very ionic LiF crystal, the net atomic charge of a quantum atom is the outcome of very local electron fluxes in chemical bonds as a result of differences in electronegativity. If we further divide each quantum atom into real space regions associated to bonds or lone pairs (by intersecting the atomic basins with ELI domains, for instance) a new perspective appears. For instance each $\mathrm{C}$ atom in $\mathrm{C}_{2} \mathrm{~F}_{4}$ will be divided in three regions, two equivalent charged sub-domains associated to each $\mathrm{C}-\mathrm{F}$ bond, and one relatively neutral region linked to the $\mathrm{C}-\mathrm{C}$ bond. What the data in Table 2 shows is that if we would compute the electrostatic interaction between the $\mathrm{C} 1-\mathrm{C} 2$ neutral sub-regions the result would not differ much from that in ethylene. This thinner partitioning, closer to chemical reasoning in a sense, comes at a price: now we should consider extra intra-atomic sub-domain electrostatic and exchange-correlation contributions, which are again far from chemical intution. If we use interacting atoms, $E_{\text {els }}^{A B}$ contains the physical Coulombic interaction between subregions which are not directly related with the short-ranged domain that chemists associate with 
Table 3: IQA data for the $\mathrm{OH}$ interaction in the $\mathrm{OH}$ and $\mathrm{H}_{2} \mathrm{O}$ molecules. Energies in $\mathrm{kcal} / \mathrm{mol}$.

\begin{tabular}{lrrrr}
\hline Molecule & $\mathrm{E}_{\text {int }}$ & $\mathrm{E}_{\text {cov }}$ & $\mathrm{E}_{\text {els }}$ & $\delta$ \\
\hline $\mathrm{OH}$ & -235.4 & -135.5 & -99.9 & 0.689 \\
$\mathrm{H}_{2} \mathrm{O}$ & -338.0 & -134.4 & -203.5 & 0.670
\end{tabular}

the $\mathrm{A}-\mathrm{B}$ chemical bond. If this is properly understood no problem appears on interpreting the positive value of $\mathrm{E}_{\text {int }}^{\mathrm{CC}}$ in $\mathrm{C}_{2} \mathrm{~F}_{4}$. It is the intrinsic energy exchanged (released or absorbed, in this case absorbed) when the two positively charged carbons interact in the molecule, which is dominated by the Coulombic repulsion between the positive regions linked to the C-F bonds.

Let us make the last arguments clearer by examining the $\mathrm{OH}$ and $\mathrm{H}_{2} \mathrm{O}$ molecules, which have been computed at the same level of theory. $\mathrm{OH}$ displays a polar bond with $\mathrm{Q}(\mathrm{O})=-0.576$ au. In water, this is $\mathrm{Q}(\mathrm{O})=-1.172 \mathrm{au}$. Table 3 shows the IQA data. It is rather obvious that the $\mathrm{O}-\mathrm{H}$ bond is pretty similar in both cases. If the $\mathrm{H}$ atom transfers 0.576 electrons to the $\mathrm{O}$ atom in $\mathrm{OH}$, the second $\mathrm{H}$ atom in water does almost the same: $2 \times 0.576=1.152$. From this point of view each $\mathrm{O}-\mathrm{H}$ bond may be considered almost independent of the other. Chemically, an unused lone pair in $\mathrm{OH}$ is used to form the second polarized $\mathrm{OH}$ link, not affecting seriously the first one. Only a small non-additivity remains. Moreover, the $\mathrm{OH} \mathrm{DI}$ is very similar in both cases (only marginally smaller in water), and so is $E_{\text {cov }}$, which differs by $1 \mathrm{kcal} / \mathrm{mol}$ in the two systems. This energetic match shows the power of real space energetic analyses to understand the origin of transferability of properties in Chemistry. Now $\mathrm{E}_{\mathrm{els}}$ comes in. Since the oxygen's charge doubles on going from $\mathrm{OH}$ to $\mathrm{H}_{2} \mathrm{O}$, while the hydrogen's charge stays almost the same, $\mathrm{E}_{\mathrm{els}}^{\mathrm{OH}}$ doubles also when going from $\mathrm{OH}$ to $\mathrm{H}_{2} \mathrm{O}$. Actually the difference between $2 \times \mathrm{E}_{\text {els }}^{\mathrm{OH}}$ term in the $\mathrm{OH}$ molecule and $\mathrm{E}_{\text {els }}^{\mathrm{OH}}$ in $\mathrm{H}_{2} \mathrm{O}$ is about 4 $\mathrm{kcal} / \mathrm{mol}$, and this difference is reduced to about $0.5 \mathrm{kcal} / \mathrm{mol}$ if $\mathrm{E}_{\mathrm{els}}$ is scaled by the small net charge non-additivity of the $\mathrm{O}$ atom. The final effect is a considerably larger $\mathrm{OH} \mathrm{E}_{\text {int }}$ value in $\mathrm{H}_{2} \mathrm{O}$ than in $\mathrm{OH}$, against chemical intuition but in line with what a physicist would expect.

If we admit that the short-ranged nature of $E_{\text {cov }}$ implies that the values in the Table correspond to the chemical covalent energy of the $\mathrm{OH}$ bond, what should the equivalent short-ranged value of $\mathrm{E}_{\mathrm{els}}$ be? We may perform the following gendanken experiment: consider in the $\mathrm{OH}$ molecule three inactive lone pairs in the $\mathrm{O}$ atom plus a bond pair that we further partition into an oxygen and a hydrogen part. The short-ranged component of $\mathrm{E}_{\mathrm{els}}$ for the $\mathrm{OH}$ bond would then be the electrostatic 
attraction between these two last regions. This figure would surely be transferable to the second $\mathrm{OH}$ bond in the water molecule. However, the energetics of the $\mathrm{OH}$ moiety should now contain the $\mathrm{H}$-lone pair, lone pair-lone pair, and O-lone pair terms. In order to gain chemical transferability of the electrostatic bond components we are forced to introduce a cohort of new terms which lack immediate chemical significance. Atomic partitions offer a much simpler view, at the expense of physically clean, yet chemically alien electrostatic terms.

\section{Conclusions}

Summarizing, we expect to have convincingly shown how real space interaction energies can be used to reconcile the physicist's atomistic point of view with the chemist's description in terms of bonds. Bonds and chemical dashes are short-ranged constructions, intimately connected with exchange-correlation (or covalent) interaction energies and thus, with electron delocalization. However, whenever charge flow (charge transfer, electron density polarization, etc.) occurs within a system, Coulombic terms necessarily appear. These are long-ranged, have been conveniently forgotten in much of the chemical bonding literature, and cannot be neglected. Electrostatic terms should not enter in energetic approaches to chemical graphs. We stress that their meaning is simple but needs to be properly understood. Thanks to electroneutrality these terms tend to cancel out in the final picture. As a note of caution, we strongly discourage using plain $E_{i n t}^{A B}$ values as covalent bond strength descriptors. For that purpose $E_{\text {cov }}$ is a better suited quantity. As an example, there is a double bond between the $\mathrm{C}$ atoms in perfluoroethylene. However, their interaction energy is strongly positive. There is no contradiction here. Just a difference between the physicist's and the chemist's points of view that we have tried to explain. $\mathrm{E}_{\mathrm{int}}$ 's are intrinsic measures of the physical interaction strength between two quantum atoms. Translating this fact into the ordinary chemical bonding parlance requires taking the precautions detailed in this letter.

\section{Acknowledgements}

We thank the spanish MINECO/FEDER, grant CTQ2015-65790-P. 


\section{References}

[1] Johnston, H. S.; Parr, C. Journal of the American Chemical Society 1963, 85, 2544.

[2] Kaupp, M.; Danovich, D.; Shaik, S. Coordination Chemistry Reviews 2017, 344, 355.

[3] Bader, R. F. W. Atoms in Molecules; Oxford University Press: Oxford, 1990.

[4] Becke, A. D.; Edgecombe, K. E. J Chem Phys 1990, 92, 5397.

[5] Silvi, B.; Savin, A. Nature 1994, 371, 683.

[6] Kohout, M. Int J Quant Chem 2004, 97, 651.

[7] Kohout, M. Faradady Discuss 2007, 135, 43.

[8] Blanco, M. A.; Martín Pendás, A.; Francisco, E. J Chem Theory Comput 2005, 1, 1096.

[9] Francisco, E.; Martín Pendás, A.; Blanco, M. A. J Chem Theory Comput 2006, 2, 90.

[10] Jeziorski, B.; Moszynski, R.; Szalewicz, K. Chem Rev 1994, 94, 1887.

[11] Szalewicz, K. Comput Mol Sci 2012, 254, 2.

[12] Misquitta, A. J.; Podeszwa, R.; Jeziorski, B.; Szalewicz, K. J Chem Phys 2005, 123, 214103.

[13] Kitaura, K.; Morokuma, K. Int J Quantum Chem 1976, 10, 325.

[14] Ziegler, T.; Rauk, A. Inorg Chem 1979, 18, 1558.

[15] Ziegler, T.; Rauk, A. Inorg Chem 1979, 18, 1755.

[16] Bickelhaupt, F. M.; Evert Jan Baerends, E. J. Reviews in Computational Chemistry 2007, 15, 1.

[17] Su, P.; Li, H. J Chem Phys 2009, 131, 014102.

[18] Glendening, E. D.; Streitwieser, J. J Chem Phys 1994, 100, 2900.

[19] Kitaura, K.; Ikeo, E.; Asada, T.; Nakano, T.; Uebayasi, M. Chem Phys Lett 1999, 313, 701.

[20] Mo, Y.; Gao, J.; Peyerimhoff, S. D. J Chem Phys 2000, 112, 5530. 
[21] Azar, R. Julian; Head-Gordon, M. The Journal of Chemical Physics 2012.

[22] Martín Pendás, A.; Francisco, E.; Casals-Sainz, J. Intermolecular Interactions in Crystals: Fundamentals of Crystal Engineering; Novoa, J. A., Ed.; Royal Society of Chemistry: London 1st ed., 2018.

[23] Martín Pendás, A.; Francisco, E. Physical Chemistry Chemical Physics 2018, 20, 16231.

[24] Outeiral, C.; Vincent, M. A.; Martín Pendás, A.; Popelier, P. L. A. Chemical Science 2018, 9, 5517.

[25] Menéndez-Crespo, D.; Costales, A.; Francisco, E.; Martín Pendás, Á. Chemistry - A European Journal 2018, 24, 9101.

[26] Rafat, M.; Popelier, P. L. A. The Quantum Theory of Atoms in Molecules Wiley-VCH Verlag GmbH \& Co. KGaA: Weinheim, Germany, 2007; p. 121.

[27] Francisco, E.; Menéndez-Crespo, D.; Costales, A.; Martín Pendás, A. J Comput Chem 2017, $38,816$.

[28] Martín Pendás, A.; Francisco, E.; Blanco, M. A.; Gatti, C. Chem Eur J 2007, 13, 9362.

[29] García-Revilla, M.; Francisco, E.; Popelier, P. L. A.; Martín Pendás, A. ChemPhysChem 2013, $14,1211$.

[30] Tognetti, V.; Joubert, L. The Journal of Chemical Physics 2013, 138, 024102.

[31] Ewald, P. P. Annalen der Physik 1921, 369, 253.

[32] Martín Pendás, A.; Francisco, E. Promolden: A QTAIM/IQA code (Available from the authors upon request by writing to ampendas@uniovi.es).

[33] Andrada, D. M.; Casals-Sainz, J. L.; Martín Pendás, Á.; Frenking, G. Chemistry - A European Journal 2018, 24, 9083.

[34] Martín Pendás, A.; Francisco, E.; Blanco, M. A. Phys Chem Chem Phys 2007, 9, 1087.

[35] Gallo-Bueno, A.; Francisco, E.; Martín Pendás, A. Phys Chem Chem Phys 2016, 18, 11772. 
What interaction energy components lie behind a chemical graph? Covalency (exchange-correlation), not Electrostatics.

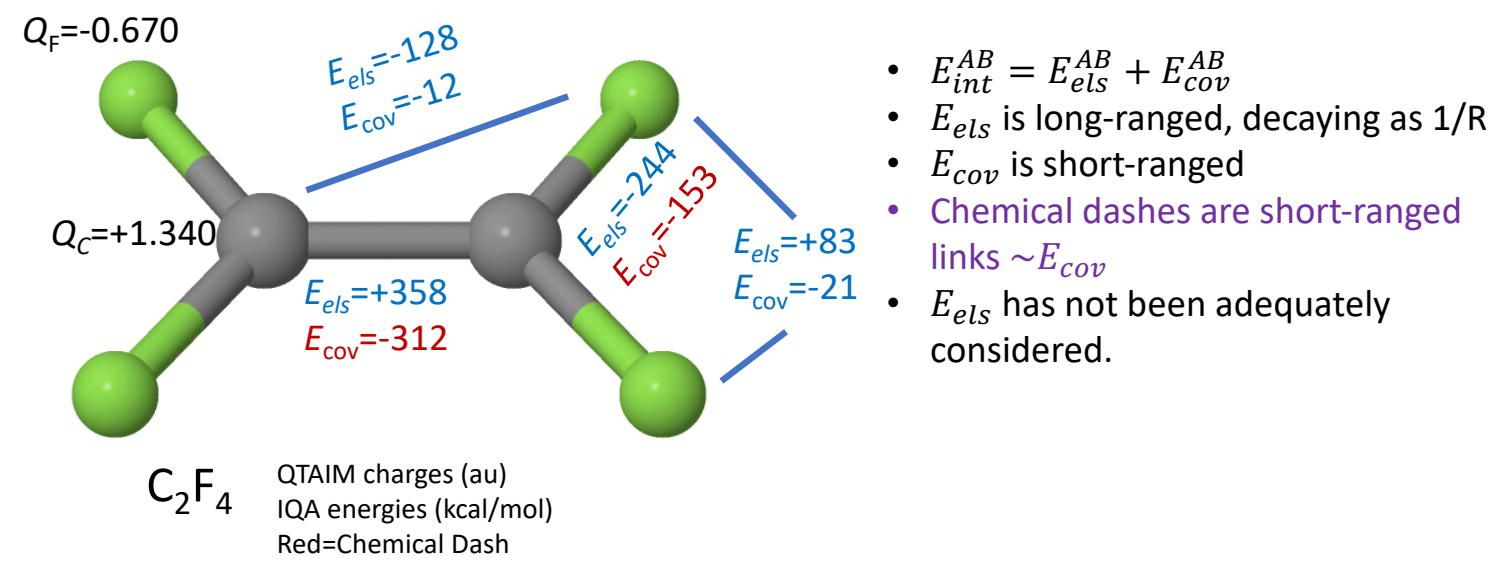

Table of Contents Graphic: Electrostatics does not build chemical graphs 